\title{
CERVANTES EN CALDERÓN
}

\section{Generalidades}

La presencia de Cervantes en la obra de Calderón ha llamado la atención de los estudiosos en repetidas ocasiones, y en este mismo congreso se dedican al tema varias intervenciones. En esos trabajos, que mencionaré enseguida, se recogen una serie de referencias con comentarios de diversa índole, que muestran ciertamente, una cantidad de evocaciones cervantinas (en torno a la veintena) en el teatro de Calderón, con distinta extensión y funciones.

Si bien es cierto que la nómina principal de referencias ha sido localizada en su mayor parte en dos trabajos pioneros, los que Alberto Sánchez y Wilson dedicaron a las reminiscencias cervantinas en Calderón ${ }^{1}$, sus comentarios se limitan prácticamente a listar las ocurrencias y añadir algunos resúmenes argumentales, sin ir mucho más allá; solo en tres ocasiones, que yo conozca, se ha intentado una aproximación más crítica, teniendo en cuenta los mecanismos de adaptación y su funcionalidad. El éxito de estas aproximaciones, a mi juicio, ha sido diverso: el análisis efectuado por Jean Cana-

1 SÁNCHEZ, 1957 y Wilson, 1982. Wilson no maneja el artículo de Sánchez. Las referencias de Wilson se completan por los editores del volumen en que apareció su trabajo póstumamente, sobre la base de anotaciones del propio Wilson, con las que señala HERRERo en 1930, pp. 360-408. Sánchez sí maneja, en cambio, otro trabajo más temprano en el que se recogían ya algunas de estas referencias: RiUs, III, 1905, pp. 8-9. Consúltese también NAVARRo, 1964, pp. 275-80. Ya redactado este trabajo José Carlos de Torres me facilita el suyo recién publicado, de interés máximo para el tema que me ocupa. Aunque no lo haya podido usar para la ponencia presente, su lectura es imprescindible. Ver, pues, ahora, J. C. DE TORRES, 1998. 
vaggio $^{2}$ sobre la reescritura de La cueva de Salamanca de Cervantes en El Dragoncillo de Calderón es buena muestra de lo que un análisis inteligente puede revelar sobre este fenómeno intertextual, mientras que las deducciones de ter $\mathrm{Horst}^{3}$ sobre las distintas influencias de las Novelas ejemplares en comedias calderonianas, en especial las de La fuerza de la sangre en No hay cosa como callar, quedan en extremo vagas e imprecisas, aunque en sus páginas hay atinadas observaciones sueltas. El trabajo de Abrams ${ }^{4}$ sobre la imaginería y aspectos temáticos del Quijote en El alcalde de Zalamea, en fin, es bastante discutible en la mayor parte de sus afirmaciones y ejemplifica la tendencia a extraer conclusiones poco justificadas a partir de textos cuya relación es más que improbable.

En el estado actual de la cuestión me parece que, aunque no añada sino una pequeña cantidad de nuevos pasajes cervantinos no señalados en los estudios mencionados, puede tener interés examinar de manera algo más sistemática las referencias aludidas. $\mathrm{Mi}$ modesto objetivo en esta exposición será pues, el de recapitular y reexaminar las opiniones vertidas por la crítica, reuniendo y sintetizando lo dicho por estudiosos precedentes, intentando precisar algunos aspectos sobre los mecanismos de adaptación y el sentido de estas apropiaciones calderonianas de los textos cervantinos, para ordenar, quizá, el conjunto, de una manera más completa.

Wilson evoca con mucha verosimilitud ${ }^{5}$, un joven Calderón aficionado a la lectura, que seguiría con interés la producción de Cervantes, tomando detalles que luego pasarían a sus comedias. Sería de esperar una influencia relevante, pero Wilson repara, sin embargo, en la pobreza de conclusiones críticas sobre las relaciones entre «el mayor novelista español con uno de los más grandes dramaturgos de ese mismo país». Una razón principal que aduce con cierta ambigüedad $^{6}$, sin que sepamos muy bien en qué grado

2 CANAVAggio, 1988.

3 R. TER HORST, 1982a, pp. 69-170; ver también TER HORST, 1982b.

4 ABRAMS, 1966.

5 WILSON, 1982, pp. 9-10.

6 Ver Wilson, 1982, p. 9. Califica de estereotipo la polaridad señalada, pero no hay una discusión operativa sobre la misma en su artículo. Esta oposición es verdaderamente un estereotipo muy nefasto, que ha perjudicado enormemente a Calderón, natural de un país en el que ciertos sectores intelectuales y de gentes «de la cultura» son afectos radicales a estereotipos y proclives a una pereza mental digna de mejor causa. Ver para una sensata denuncia de esta actitud el significativo trabajo de K. REICHENBERGER, 1997: «Los eruditos finiseculares, en busca de un héroe portavoz de sus ideas, decretaron que Calderón era un conservador de cabo a rabo... No por repetir el veredicto a lo largo de medio siglo resultaba este más verdadero, sino solo más pronunciado: Calderón, el reaccionario» (p. 31). En este fin de siglo (otro más) siguen ciertos sectores cultivando la imagen de los aludidos eruditos finiseculares... Aquellos, por lo menos, se habían leído a Calderón (mal, pero se lo habían leído). 
la rechaza o la acepta parcialmente, es la diferencia de ambos escritores:

Por supuesto, Calderón y Cervantes parecen muy distintos entre sí. Cervantes tenía una imagen del ser humano positiva y de largo alcance, al tiempo que un gran sentido del humor y numerosos contactos fuera del mundo de las letras. La imagen que Calderón tiene de la sociedad parece a primera vista limitada a la esfera de los hidalgos, los santos, los bandidos y los sirvientes, y ha habido pocos críticos dispuestos a reconocerle el más mínimo sentido del humor.

Esta distancia entre las supuestas concepciones vitales de ambos explicaría la falta de contacto. Sucede que efectivamente, puede decirse - como intentaré mostrar en lo que sigue-, que las concomitancias no son excesivas, aunque sí notables. Pero las diferencias no obedecen a esa tópica polaridad totalmente falsa, y sumamente injusta con Calderón, que todavía pervive, sino a otros motivos de índole principalmente artística.

El predominio de la figura de don Quijote en las referencias calderonianas, explicable por la misma fuerza de la creación cervantina, a la vez que la lectura eminentemente cómica que se hizo en su época del personaje, y que es la vigente en Calderón, explica su restricción a perspectivas jocosas, que lo expulsan de las posibilidades serias del drama o la tragedia. De ahí que se localicen casi siempre estas referencias en los pasajes de graciosidad, encomendados a los locutores del donaire, como objeto de chistes momentáneos o excusa para una burla ingeniosa. Como apunta Sánchez ${ }^{7}$, en palabras que requerirán alguna matización, pero que en lo sustancial podría suscribir:

En todas las aducidas referencias quijotescas de Calderón apenas hay crítica del personaje cervantino, ni interpretación siquiera. Son visiones caricaturescas en su mayoría, como las que se prodigaron en mojigangas y festejos populares. Pero lo que no puede negarse es el recuerdo frecuente del héroe cervantino, lo que entraña una admiración singular.

La complejidad psicológica y técnica de las novelas de Cervantes, por otra parte, exige ciertos requisitos difícilmente compatibles con el ritmo dinámico de la comedia nueva: el relato y la comedia tienen imperativos genéricos muy distintos, y los relatos cervantinos son demasiado complejos para permitir adaptaciones teatrales sin grandes modificaciones que exigen probablemente excesiva inversión de energías ${ }^{8}$. De hecho es difícil observar transposiciones importan-

\footnotetext{
7 SÁNCHEZ, 1957, p. 267.

8 Puede verse a modo de ejemplo el caso de la adaptación que hace GuiLLÉN DE CASTRO de El curioso impertinente, del que me he ocupado en ARELlANO, 1998, $\mathrm{y}$ en el que se perciben bien algunos problemas de este tipo de adaptación.
} 
tes en este sentido. A pesar de la gran influencia que ha visto ter Horst de las Novelas ejemplares en Calderón, a las que considera, junto con el Quijote, «a major literary influence» en los años de formación del dramaturgo ${ }^{9}$, es problemático demostrar que ciertos rasgos del tratamiento del honor en el teatro de Calderón procedan precisamente de textos como La fuerza de la sangre, o como sugiere Wilson ${ }^{10}$, de El celoso extremeño y El curioso impertinente; la formación y desarrollo de ese código tiene muchas otras raíces, evidentemente ${ }^{11}$.

No menos problemática de demostrar es la derivación cervantina del uso de ovillejos en el teatro de Calderón, como apunta Sánchez, que relaciona con los ovillejos de Cardenio en el Quijote, con los de La fiera, el rayo y la piedra o de autos como Tu prójimo como a ti... No hay que olvidar que en el teatro, por ejemplo, Tirso de Molina, cuya obra conoce bien Calderón, es muy aficionado a las ingeniosidades métricas, y cultiva el ovillejo, que por otra parte es estrofa de libre disposición, aunque rara. Por la misma razón, resulta improbable ${ }^{12}$ que la idea de El gran teatro del Mundo proceda del Quijote (II, 12, la vida como comedia): es un motivo tópico infinitamente glosado y reiterado, mostrenco.

Por fin, dentro del campo estrictamente teatral, que sería el más inmediato, la posible influencia cervantina queda muy restringida por el fracaso de la fórmula teatral de Cervantes frente a la lopiana, coyuntura que explica también por qué el teatro de Cervantes no puede funcionar como modelo importante para Calderón.

Teniendo en cuenta estas premisas a modo de hipótesis de trabajo, me parece que puede ser útil revisar la presencia de Cervantes en Calderón, observando los marcos diferentes de inserción y las diferentes necesidades y convenciones de escritura.

9 R. TER HORST, 1982b, p. 34. En 1982a dedica un extenso capítulo a detallar esta influencia; me ocuparé de este asunto más adelante.

10 Wilson, 1982, pp. 17-18. Cree, por ejemplo, Wilson, que elementos como la responsabilidad del marido (presentes en los dramas de honor de Calderón) se pueden relacionar con novelas cervantinas como las citadas, etc. Pero estas posibles relaciones se mantienen en un plano de generalidad y vaguedad que no permiten una conexión directa fructífera.

${ }_{11}$ La elaboración del código del honor es muy amplia y variada, y se advierte también con riqueza llamativa en el teatro de Lope. Ver para el código del honor y sus muy variados componentes y raíces, Claude Chauchadis, 1997 (para Cervantes, pp. 305-24), donde se hallarán todas las documentaciones y bibliografía pertinentes.

12 SÁNCHeZ, 1957, pp. 269-70. Pero el mismo crítico recuerda la topicidad del motivo, y su comentario desde luego no demuestra la relación Cervantes-Calderón, sino más bien el hecho de que ambos (como otros muchos escritores) usan el motivo. 
Vayamos pues, con la revisión de esta presencia, empezando por lo que llamaré referencias microtextuales, y siguiendo con las macrotextuales.

\section{REFERENCIAS CERVANTINAS MICROTEXTUALES EN CALDERÓN}

Denominaré referencias microtextuales a las menciones ocasionales que se se expresan en muy pocos versos (entre dos y diez o doce), sin que articulen ningún esquema argumental ni la definición de los personajes, a los que solo confieren pequeños rasgos no esenciales. Generalmente suponen una asociación jocosa, o dan pie a un juego de ingenio a partir de la evocación intertextual, constituyendo una agudeza por alusión a textos conocidos por el público, que se complacen en reconocer la broma.

A esta categoría pertenecen la mayor parte de los pasajes cervantinos recordados por Calderón, sobre todo los que apuntan al Quijote, y en particular al ingenioso hidalgo protagonista, aunque esta obra no es la única fuente evocada. En Saber del mal y del bien (Dramas, p. 224), por ejemplo, el criado García es un fanfarrón cobarde, que desafiado burlescamente por Julio, saca la espada y toma la postura del valentón del soneto "Voto a Dios que me espanta esta grandeza», que Cervantes tenía por honra principal de sus escritos (Viaje del Parnaso, IV). El valentón cervantino, tras hacer sus fieros «caló el chapeo, requirió la espada, / miró al soslayo, fuese, y no hubo nada» (vv. 16-17 del estrambote), y García asegura que sacará la espada "y con gran desembarazo / revuelta la capa al brazo, / calo el sombrero, voyme y no hago nada». El gesto (sacar la espada), el léxico («caló el chapeo» / «calo el sombrero»), la cercanía de la paráfrasis ( «fuese, y no hubo nada» / "voyme y no hago nada») denuncian una directa intertextualidad, ya advertida por Valbuena.

En la cueva de La gran Cenobia (Dramas, p. 86: "Aquí / se ve una profunda cueva. / Aventura es esta nueva») ${ }^{13}$, la referencia a una "aventura nueva» de gruta contiene sin duda un eco del episodio quijotesco de la Cueva de Montesinos (II, 22-23), calificada por el narrador de "peligrosa y nueva aventura» (II, 22). Calderón utiliza estas evocaciones para proporcionar a su texto, de manera sumamente económica, una serie de connotaciones: rasgos caricaturescos de un valentón en el primer caso, misteriosa aventura fantástica en el segundo, pero la extensión textual es muy pequeña.

13 En lo que sigue localizaré las comedias de Calderón que cite por las Obras completas editadas por Valbuena con la indicación Comedias o Dramas, y la página. Si se usa otra edición se indicará pertinentemente. 
A un tipo de situación muy precisa responden la mayor parte de los pasajes localizables referidos al Quijote, a menudo en una comedia de capa y espada - otras veces en palatinas o novelescas; rara vez en tragedias-, donde el prurito de honor y valentía de los galanes puede ser mirado en clave irónica y burlona por el gracioso, en cuya boca encontramos la casi totalidad de estas alusiones cervantinas, relativas a la figura de un don Quijote ridículo, visto como un caballero loco, absurdo protector de damas en peligro. Así sucede en Argenis y Poliarco (Comedias, p. 1936) en boca de Gelanor, el criado de Poliarco, que se burla de su amo aduciendo la figura ridícula de un caballero entrometido que remite sin duda a don Quijote:

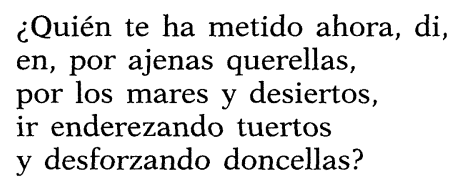

Se trata de una alusión general que estriba en el uso de un vocabulario característico, pero frecuentemente la mención es explícita, como en El maestro de danzar (Comedias, pp. 1541), en boca del gracioso Chacón, que se dirige a su amo Enrique:

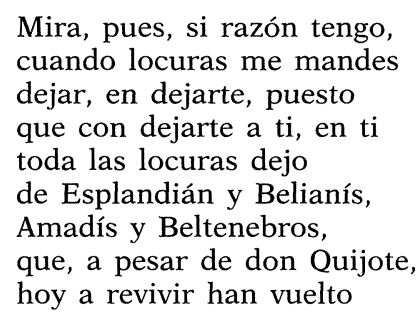

Esta ocurrencia es un tanto extraña en el corpus calderoniano. Se contrapone don Quijote a los caballeros andantes ejemplos de locuras amorosas, lo que hace pensar que aquí la referencia no es al protagonista sino al libro mismo, y a su confesado objetivo (Prólogo de la Primera parte) de deshacer la máquina de los libros de caballerías.

El resto de las advertidas responden al modelo mayoritario apuntado, con función caracterizadora de personaje: véanse los pasajes de Manos blancas no ofenden (Comedias, p. 1115):

\footnotetext{
de uno en otro disfraz hoy de resucitar tratas

la andante caballería,
} 
que ha mil siglos que descansa en el sepulcro del noble don Quijote de la Mancha

O de Dicha y desdicha del nombre (Comedias, p. 1810), con cita también de Sancho Panza, con quien se identifica Tristán, burlándose de su amo defensor de unas damas tapadas agredidas por unas máscaras en carnaval:

$$
\begin{array}{ll}
\text { FLORA. } & \text { ¿De dónde nos vino este } \\
\text { don Quijote de la Mancha? }
\end{array}
$$

Y parecida función reviste en Basta callar (Comedias, p. 1733), en donde la mención le sirve al gracioso Capricho para burlarse del pundonor del Conde, que quiere castigar el despecho causado a unas damas, lo que comenta el criado:

$$
\begin{aligned}
& \text { Don Quijote no podía } \\
& \text { hacer más }
\end{aligned}
$$

La exhibición de ingenio exigida por la estética del conceptismo provoca diversas variaciones del motivo básico, buscando el juego verbal o la acumulación de agudezas. Los pasajes de Mañana será otro día (Comedias, pp. 765, 768 y 774) explotan la creación neológica: "Enquijotóse mi amo», "basta una quijotada / en un día», o la parodia de frases hechas: «de amparador / juraste ayer el oficio, / don Quijote de prestado»...

La variación consiste en otros casos en aplicaciones metafóricas insertadas en contextos de ingeniosa discusión de academia literaria, propios del género palatino. En La banda y la flor (Comedias, pp. 425-26), Clori y Nise discuten si la primacía ha de otorgarse a la noche o a la aurora, en una estructura característica de las academias de ingenio, muy repetida en la comedia palatina del Siglo de Oro. Al terciar 'don Enrique en defènsa de la aurora Nise lo califica de "Don Quijote de la aurora", sumando en su expresión las connotaciones de 'defensor enamorado de la aurora' y 'entrometido' ("¿qué le importa que al albor / beba una y otra flor / las lágrimas que ella llora?»).

En un drama novelesco situado en el antiguo Egipto, Los hijos de la Fortuna (Dramas, p. 1234), precedido de la Historia Etiópica de Heliodoro ${ }^{14}$, la mención de don Quijote de la Mancha supone

14 Cervantes adopta el esquema del relato bizantino en el Persiles; Pérez de Montalbán hace una comedia de Teágenes y Cariclea... Hay otras muchas adaptaciones novelescas: ver GonZÁLEZ RoviRA, 1996. 
un anacronismo burlesco, tipo de recurso muy utilizado por la meiosis satírica, y una de las formas favoritas de lo que ha llamado Claire Pailler "guiños» de Calderón ${ }^{15}$, capaces de instaurar un distanciamiento irónico, una ruptura de la ilusión escénica con diversas potencialidades:

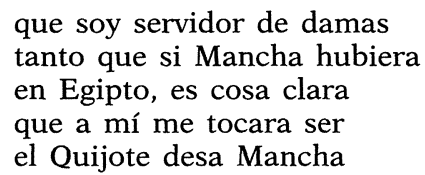

En la famosa evocación de La dama duende, el motivo básico engendra un desarrollo algo más complejo, con otros detalles asociados: a la identificación jocosa que hace Cosme de su amo con don Quijote, por haber salido en defensa de una dama tapada a la que no conoce (doña Ángela), lo que le gana una herida (Comedias, p. 241: «Qué bien merecido tiene / mi amo lo que se lleva, / por que no se meta a ser / don Quijote de la legua»), le sigue, en la aventura de la dama duende, la parodia de la fabla medieval en las cartas del galán (Comedias, p. 250, carta que firma «El caballero de la Dama duende»), imitada, claro está, de los discursos del ingenioso hidalgo.

Como se ve, el personaje de don Quijote concentra la mayor parte de las ocurrencias. Rara vez la comparación se establece con otro personaje, aunque el mismo Rocinante servirá en La niña de Gómez Arias (Dramas, p. 805) para calificar el discurso de unos caballos que se quejan "en rocinantes palabras".

Sí se pueden sumar, en cambio, algunos otros episodios al de la Cueva de Montesinos que he apuntado antes; hay una mención al paso a la aventura de los molinos de viento en El sitio de Bredá (Dramas, p. 114) ${ }^{16}$, provocada por los molinos de los Países Bajos ( ¿ ¿Molinos de viento? Ya / me parece su demanda / aventura del famoso / don Quijote de la Mancha»), y otras utilizaciones de la aventura de Clavileño en El astrólogo fingido, de la de la carreta de las Cortes de la Muerte en la Mojiganga de las visiones de la Muerte, y de don Quijote en el don Mendo de El alcalde de Zalamea, pero todos estos últimos casos citados pertenecen ya a lo que denomino macrotextos, con usos más complejos, que examinaré en el apartado siguiente.

Fuera del Quijote se cuentan algunos otros microtextos procedentes del campo de las Novelas ejemplares.

15 PAILler, 1980

16 De otras posibles presencias cervantinas en esta comedia me ocupo más adelante. 
En primer lugar, Calderón aprecia obviamente el ingenio fabulador de Cervantes, al que pondera repetidamente como gran trazador de historias. En términos generales aparece este juicio en Casa con dos puertas (Comedias, p. 282):

$$
\begin{aligned}
& \text { para que de aquí se enlace } \\
& \text { la más extraña novela } \\
& \text { de amor, que escribió Cervantes }
\end{aligned}
$$

Cervantes narrador de extrañas y sorprendentes novelas de amor se menciona de nuevo en Los empeños de un acaso (Comedias, p. 1045) pasaje en que el gracioso Hernando enuncia sus aspiraciones amorosas a una dama

$$
\begin{aligned}
& \text { extravagante y sujeto } \\
& \text { capaz de novela, porque } \\
& \text { es mi amor tan novelero } \\
& \text { que me le escribió Cervantes }
\end{aligned}
$$

Amén de estas ponderaciones generales Calderón menciona algunas novelas en concreto: en Casa con dos puertas (Comedias, p. 306) Calabazas se define a sí mismo como "curioso impertinente» ante una pesquisa de don Félix, con aplicación dilógica del título de la novela inserta en el Quijote. De las ejemplares se recuerda al Celoso extremeño en dos ocasiones interesantes que sirven para modelar la imagen de un espacio y de un personaje respectivamente. En la comedia de El escondido y la tapada es muy importante el escenario de casa cerrada, con cuarto secreto. El protagonista ha de permanecer escondido en el cuarto disimulado en la escalera de una casa, entre otras razones, porque la casa queda súbitamente abandonada y cerradas todas sus salidas, dejando al galán dentro. La descripción de la casa se culmina y sintetiza en la comparación con la famosa del celoso Carrizales, prototipo de encierro riguroso:

$$
\begin{aligned}
& \text { Esta es la casa sin duda } \\
& \text { que aquel famoso extremeño } \\
& \text { Carrizales fabricó } \\
& \text { a medida de sus celos, } \\
& \text { pues no hay puerta ni ventana, } \\
& \text { guarda, patio ni agujero } \\
& \text { por donde salga un mosquito } \\
& \text { (Comedias, p. 686) }
\end{aligned}
$$

$\mathrm{Al}$ retrato de un personaje obedece la segunda ocasión aludida, de Antes que todo es mi dama (Comedias, p. 879), en donde el viejo padre de Laura, guardián del honor, se define en boca de la criada 
Beatriz, como un "extremeño de honor», una verdadera copia o traslado «bien y fielmente sacado / del celoso Carrizales».

También hay duelo en la damas, ofrece, en cambio, un juego chistoso mediante la alusión al Licenciado Vidriera, que no tiene aquí otro sentido que el mero juego con el nombre. No hay mayor evocación de los sucesos o personajes de la novela cervantina. Es simplemente un chiste basado en la alusión. En el diálogo de Simón e Isabel (gracioso y criada), el gracioso, sin conocerla (va tapada) le atribuye jocosamente un ojo de vidrio, lo que da pie a la criada a burlarse de una joya que él ostenta:

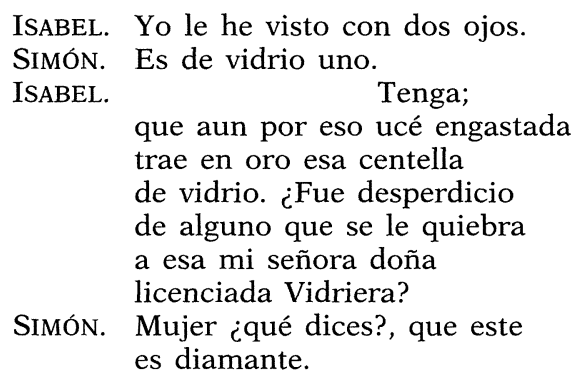

(Comedias, p. 1523)

Más amplia consideración pide la posible influencia de La fuerza de la sangre en No hay cosa como callar, y a ello me referiré más adelante.

Puede, en suma, decirse, para cerrar este apartado, que los microtextos cervantinos en Calderón, muestran una variedad de aplicación y mecanismos de inserción bastante notable, a pesar de su poca extensión textual y de su poca trascendencia en el trazado de las comedias. Sirven a la caracterizacion de personajes, a la evocación de un espacio dramático, o constituyen oportunidad para elaborar chistes ingeniosos. Se localizan preferentemente en la comedia de capa y espada o palatina, y en todo caso, en pasajes de graciosidad, y vienen encomendados constantemente a los locutores del donaire (graciosos y criadas). Por su origen predomina el Quijote, tanto en el recuerdo del protagonista como en el de algunos episodios o situaciones. Las Novelas ejemplares concentran el resto de menciones (Celoso extremeño, Licenciado Vidriera, La fuer$z a$ de la sangre), exceptuando algún raro caso en que la alusión procede de la poesía.

De estas mismas fuentes y del teatro proceden otro tipo de textos, de mayor incidencia, que analizaré a continuación. 


\section{MacroteXtos CERVANTINOS EN CALDERÓN}

\subsection{El astrólogo fingido y la aventura de Clavileño (Quijote, II, 41)}

Hay una escena en El astrólogo fingido que para Valbuena ${ }^{17}$ "es la huella cervantina más concreta en Calderón. El paralelismo entre las escenas de don Quijote y Clavileño y Otáñez y su encantamiento, es evidente». Se trata de un episodio que Wilson ${ }^{18}$, analiza con cierto descuido, considerándolo presentado «en forma algo precipitada en la última escena, sin haber sido anticipado", pero que en realidad Calderón adapta de manera espléndida a la trama y objetivos de su comedia. Por una serie de enredos, muchos personajes de la comedia se empeñan en considerar a don Diego astrólogo eminente. Hacia el final de la obra, que construye sus máquinas en progresión creciente, varios personajes acuden a don Diego para hacerle sucesivas peticiones absurdas confiadas en su supuesta capacidad mágica: Violante le pide ayuda en sus amores, don Carlos lo mismo, el viejo Leonardo quiere que le encuentre una joya perdida, y por fin Otáñez, escudero montañés, le pide que lo traslade a la Montaña por vía mágica, para ahorrarse la costa del viaje. El criado Morón pide a su amo que le deje ocuparse del asunto y empieza la trama de la burla de que el escudero será objeto. Es, pues, una burla provocada por una de las peticiones absurdas con que los personajes acuden al astrólogo: refleja en clave más grotesca la misma sátira ejercida sobre los demás crédulos. La misma burla se construye cuidadosamente en varios tiempos: momento de la petición, en que Morón, por medio de apartes, indica al público que se propone burlar al vejete, al tiempo que da instrucciones a éste para que vaya ridículamente vestido con botas, espuelas y papahigo; momento de ejecución. en que ata a Otáñez con los ojos vendados a un banco del jardín y le hace creer que va volando sobre un sastre demonio, y momento de la revelación de la burla, que se coloca en el desenlace de la comedia, donde se revelan el resto de las burlas. No es, pues, una escena que Calderón ponga al final de manera fortuita, como si no quisiera perder una oportunidad cómica, sino que está perfectamente pensada como culminación jocosa de una trama de credulidades ridículas objeto de sátira, concebida en modo especular al trasladar a los dos personajes subalternos, en clave más ridícula aún, la relación establecida entre los otros peticionarios y el astrólogo fingido.

\footnotetext{
17 Nota preliminar a la comedia en Comedias, p. 128.

18 Wilson, 1982, pp. 10-11.
} 
La conexión con la aventura de Clavileño es evidente, pero los elementos de la adaptación dramática son muy notables, y conviene subrayar la explotación del conflicto cómico entre dos personajes graciosos, el criado Morón y el escudero Otáñez, tipo figura, montañés orgulloso de su hidalguía, que protagonizan un conato de duelo de pullas con acusaciones de judaísmo y mentís. Por lo demás el episodio del Astrólogo mezcla la tradición del viaje mágico, a espaldas de demonios o monturas diabólicas, bien estudiada por Caro Baroja, y la del caballo de madera volador, que es la principal reflejada en el Quijote, aunque ambos motivos se presentan ya fusionados en la misma tradición anterior a la comedia ${ }^{19}$.

\subsection{La púrpura de la rosa y La casa de los celos}

Mayores modificaciones y menos relación directa cabría advertir en la imitación que podría señalarse en La púrpura de la rosa, cuya cueva de los celos podría evocar detalles de la otra cueva de los celos que Cervantes presenta en La casa de los celos y selvas de Ardenia. En ambas aparecen personajes alegóricos ${ }^{20}$ con objetos que emblematizan su sentido (Temor, Sospecha, Desengaño, Desesperación...). Dos son comunes, el Temor y la Sospecha. La estructura de la alegoría es diferente en ambos poetas. Los personajes alegóricos de Cervantes no hablan: funcionan como ilustraciones visuales que explica el mago Malgesís, mientras que los de Calderón elaboran un discurso rico en fórmulas correlativas y paralelísticas, de mayor expresividad dramática. Parece razonable pensar en cierto grado de evocación, ya que el motivo y los dos personajes comunes son pistas a mi juicio importantes. Pero no habría que exagerar esta coincidencia: Calderón es un maestro de los personajes alegóricos y los cultiva en numerosas ocasiones, sobre todo en los autos, como es sabido, donde pasiones como las de La púrpura de la rosa, o seme-

19 Ver para estos motivos CARO BAROJA, 1992, I, pp. 231-94 y las notas correspondientes al episodio en la edición del Quijote citada en la bibliografía. Recuérdese que en el mismo episodio de Clavileño don Quijote saca a colación el famoso viaje a Roma del licenciado Torralba, a quien llevaron los diablos caballero en una caña.

20 Wilson, 1982, pp. 11-13 señala que «Calderón se apropió de la alegoría de Cervantes modificándola y desarrollándola en sentido operístico». No se ve exactamente en qué consiste este desarrollo operístico. Observaciones más precisas hacen los editores de La púrpura de la rosa, pp. 85-87 de ed. citada en bibliografía. Más lejano del pasaje de la comedia es el romance cervantino dedicado a la morada de los celos, que empieza "Yace donde el sol se pone», que su autor confiesa estimar mucho en Viaje del Parnaso, IV. Una versión de este romance figura como anónimo en el Romancero general de 1600. 
jantes tienen un largo desarrollo escénico, y por demás la descripción de la morada de los celos es elemento reiterado en otras obras como L'Adone de Marini, la Octava Rima de Boscán o el Orlando furioso de Ariosto (XLII, 46-54).

\subsection{El sitio de Bredá y La Numancia}

También problemática, por otras razones ${ }^{21}$, es la posible influencia de El cerco de Numancia en El sitio de Bredá, aunque me inclino a creerla efectiva, como Valbuena ${ }^{22}$, quien apunta que «es la tragedia El cerco de Numancia de Cervantes la obra que ha tenido principalmente como modelo para la redacción de ciertos aspectos de la pieza». No me parece definitiva la mención de Numancia (Dramas, p. 130), que podría ser a la ciudad misma, ni los detalles de las estrategias del cerco, conocidos por otras fuentes y fundados en la propia realidad histórica y militar, como otros elementos comunes que muy bien podrían responder a materiales mostrencos, pero la acumulación de todos ellos y algunos pasajes bastante cercanos apuntan a una conexión real. Las escenas patéticas y descripción del estado de la ciudad sitiada, con referencia a la pestilencia, hambres y suicidios parecen derivarse de las cervantinas (Dramas, pp. 126, 129; Cervantes, Teatro completo, pp. 964-65, passim), tanto más cuanto este motivo queda mucho más desplazado en Calderón, cuya obra no es una tragedia como la de Cervantes, sino una comedia bélica de celebración triunfal con elementos galantes, según comentaré enseguida. Dicho de otro modo: estos elementos son poco pertinentes en la trama global de Calderón y se explican más satisfactoriamente si se interpretan como evocación de la pieza cervantina. La decisión de matar a los habitantes inútiles para la lucha y consumidores de provisiones (Teatro completo, p. 970) en la Numancia, se adapta en la de expulsar de la ciudad a las mismas categorías de habitantes en El sitio de Bredá (p. 120); comunes son las actitudes de Escipión y los nobles españoles de acudir a las

${ }^{21}$ La Numancia no se publicó hasta 1784 , por Sancha. Existen dos manuscritos (en la Biblioteca Nacional de Madrid y en la Hispanic Society de Nueva York) de finales del XVI o pricipios del XVII. Desconocemos otros detalles del éxito de la comedia (bastante, según el propio Cervantes) y de sus representaciones, pero es probable que Calderón la conociera. Los detalles señalados arriba lo hacen suponer.

22 Dramas, p. 104; y continúa: «En una y otra el concepto de fama es fundamental para entender el sentido buscado por el autor. Similares recursos estratégicos se emplean en ambos sitios. La protesta de las mujeres ante los rigores impuestos por la defensa de la plaza es también pararela... Calderón hace alusión a aquella obra en forma inequívoca: “¿Es Bredá acaso Numancia?”». 
tareas del cerco para servir de ejemplo a los soldados, sin rechazar el trabajo manual:

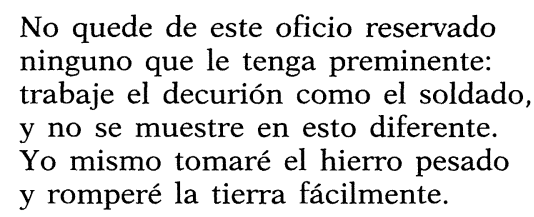

(CERvantes, Teatro completo, pp. 929-30)

—¿Qué esperamos, caballeros?

Nosotros hemos de ser

a esta facción los primeros.

-Así a nuestra imitación

veréis como acuden luego

los soldados.

(Toman todos espuertas, azadones y hachas.)

(Dramas, p, 118)

Y común es la exposicion de la doctrina de que es preferible una victoria sin sangre, con cercanía léxica incluso:

... yo fío

que los que fueren prácticos soldados
dirán que es tener mayor en cuenta
la victoria que menos es sangrienta

(Teatro completo, p. 955)

\begin{abstract}
... que la gloria
es más prudente y modesta

y más noble cuando cuesta

menos sangre la victoria
\end{abstract}

(Dramas, p. 108)

En mi opinión Calderón evoca una serie de motivos cervantinos que le parecen apropiados para un ambiente de cerco que atrae inmediatamente el ejemplo de Numancia: los motivos patéticos, algunas referencias concretas a actitudes o episodios de la tragedia de Cervantes, etc. Pero es evidente que se trata de dos obras muy distintas, con enfoque y objetivos muy diferentes. Para empezar, aunque en ambas piezas los dos contrincantes tienen dimensión heroica, el protagonista en La Numancia es el pueblo asediado (identificado con España por medio de la figura alegórica de España), mientras que en El sitio de Bredá es el ejército sitiador de los españoles. La jerarquía heroica en la que los españoles ocupan el primer nivel, es totalmente distinta. Los españoles son en un caso los 
sitiados; en el otro los sitiadores. A partir de aquí la economía de las acciones debe seguir caminos distintos. Para llegar a la glorificación heroica los numantinos han de ser destruidos, convirtiéndose en mártires de la libertad ${ }^{23}$ : por eso en el arranque de la tragedia Escipión se niega a admitir la rendición de los enemigos, que le ofrecen someterse. Con esta actitud de Escipión no queda otro camino que el desenlace de total pérdida. En El sitio de Bredá, para poder mostrar la valentía de los españoles es necesario vencer a un enemigo que se muestra opuesto a la rendición, pero el sitiador tiene que revelar su magnanimidad y clemencia: por eso en el desenlace los sitiados se rinden y son respetados.

Todas estas diferencias se justifican también por imperativos del género: tragedia en un caso, comedia bélica celebrativa en otro, escrita en la circunstancia del hecho histórico (rendición de Breda en 1625). Las escenas galantes de El sitio de Bredá entre damas sitiadas y militares españoles, carecerían de sentido en la tragedia cervantina, pero no en una pieza optimista concebida como triunfal exaltación de la nobleza, valor y justicia de las tropas españolas, que muestran también su liberalidad y lealtad, frente a otros soldados tudescos o valones, que esperan con avidez el saqueo de la ciudad, impedido por la generosidad del conquistador Espínola.

\subsection{Don Mendo de El alcalde de Zalamea y don Quijote de la Mancha}

Sobre la condición quijotesca del personaje del hidalgo ridículo don Mendo en El alcalde de Zalamea hay opiniones contrapuestas, desde la de Wilson ${ }^{24}$, que ve a la pareja Mendo-Nuño muy poco integrada en la trama central, a la de Abrams ${ }^{25}$, para quien hay «marcada influencia del Quijote a través de los tres actos», no limitada a esta caricatura.

Sánchez, por su parte ${ }^{26}$ considera este personaje como un carácter esbozado a imitación ligera del hidalgo manchego, y realmente emparentado con el escudero del Lazarillo.

El personaje de Mendo evoca indudablemente a don Quijote, con comparaciones explícitas en el texto de Calderón:

23 Dice EsPaña, Teatro completo, p. 931: «Sola Numancia es la que sola ha sido / quien la luciente espada sacó fuera / y a costa de su sangre ha mantenido / la amada libertad suya primera».

24 WILSON, 1982, p. 11

25 ABRAMS, 1966, p. 27.

26 SÁNCHEZ, 1957, p. 267. 
un hombre

que de un flaco rocinante a la vuelta de esa esquina se apeó, y en rostro y talle parece aquel don Quijote de quien Migel de Cervantes escribió las aventuras

$$
\text { (vv. } 213 \text { y ss.) }
$$

La relación con el escudero del Lazarillo es igualmente obvia ${ }^{27}$. Desde el punto de vista de la dimensión cervantina, la mayor parte de las inferencias de Abrams me parecen muy inseguras. Así, por ejemplo, la coincidencia de la frase «haz lo que te manda tu amo y sentarte has con él a la mesa" (la dice don Quijote a Sancho, II, 29, y la vuelve al revés burlonamente Nuño 'aunque haga lo que su amo le manda no se sentará con él a la mesa, porque no tiene mesa', vv. 343-46) ${ }^{28}$ es discutible, si tenemos en cuenta su extendido carácter proverbial y sobre todo la diferencia de los contextos. La esperanza de realizar el deseo en solo un día (idea presente en la segunda jornada de la comedia) tiene poco que ver con la idea del poema de don Lorenzo, el hijo del caballero del Verde Gabán (Quijote, II, 18): la expresión de El alcalde de Zalamea tiene mejores paralelos en la propia obra de Calderón, como en otro pasaje de No hay cosa como callar (Comedias, p. 1001). Compárense un par de fragmentos:

\author{
En un día el sol alumbra \\ y falta; en un día se trueca \\ un reino todo... \\ De una sola vez a incendio \\ crece una breve pavesa; \\ de una vez sola un abismo \\ fulgúreo volcán revienta, \\ de una vez se enciende el rayo \\ que destruye cuanto encuentra \\ (Alcalde de Zalamea, vv. 969 y ss.)
}

27 Del retrato del Lazarillo toma Calderón, por ejemplo, el motivo concreto del palillo de dientes, expresión del hambre disimulada del hidalgo miserable (el motivo pasa al Quijote, pero en contexto algo diferente). Otro dato concreto imitado del Quijote es el de las armas viejas de Mendo, puestas en un azulejo sobre el marco de la puerta (vv. 947 y ss.) como tiene don Quijote su lanza en el astillero, etc. Por otra parte es motivo tópico que aparece en otros textos: ver las notas de EscuDERO a la ed. cit. de El alcalde de Zalamea.

28 ABRAMS, 1966, p. 28. 
La muerte da un basilisco

de una sola vez que vea,

la víbora da la muerte

de una sola vez que muerda;

la espada quita la vida

de sola una vez que hiera,

y de una vez sola el rayo

mata aun antes que se sienta

(Dramas, p. 1001)

Se trata de funciones dramáticas propias del ritmo acelerado de la comedia y que justifican la velocidad con que los galanes se enamoran. El texto del Quijote aducido por Abrams es:

\section{Si mi fue tornase a es sin esperar más será, o viniese el tiempo ya de lo que será después}

Que en realidad se trata de un mote ajeno ${ }^{29}$, sobre el que se desarrolla a continuación una glosa en la que don Lorenzo lamenta la rapidez con la que el tiempo pasa y se lleva la dicha, deseando poder volver al pasado.

No hay, en suma, ninguna relación en estos pasajes calderonianos con el del Quijote aducido por Abrams.

Alguna más podría hallarse en la serie de consejos de Pedro Crespo a su hijo y en la de don Quijote a Sancho cuando parte para su gobierno de Barataria, pero no se advierte la estrecha cercanía apuntada por Abrams, ni en la secuencia temática ni en la índole de los consejos, cosa explicable porque unos responden al tema (adaptado paródicamente) de la educación de príncipes (Sancho va de gobernador) y los otros son mucho más cotidianos.

La superficialidad de la imitación quijotesca no debe hacer pensar, sin embargo, que el personaje de don Mendo es en sí mismo irrelevante en la obra. Las cosas son algo más complejas (y quizá en el cultivo de la complejidad es donde más se parecen Cervantes y Calderón). Pues don Mendo, con su orgullo de hidalgo hambrón, su desprecio por los villanos, su negativa a pensar en casarse con Isabel ${ }^{30}$, refleja en tono bufo la misma actitud que muestra el capi-

\footnotetext{
${ }^{29}$ Glosado ya por Gregorio Silvestre; ver notas al pasaje en la ed. cit. del Quijote.

30 «¿Pues no hay sin que yo me case / Huelgas en Burgos, adonde / llevarla cuando me enfade» (vv. 336-38), dice. Poco hace ahora al caso la ridiculez de las palabras de Mendo (en las Huelgas profesaban grandes princesas y damas nobles), sino su valor premonitorio: Isabel acabará en un convento, tras ser violada por el capitán y abandonada por éste, que la rechaza por ser gente llana.
} 
tán, funcionando como ilustración secundaria del conflicto trágico central. En otra vertiente, el hidalgüelo no establece oposición solamente, como se suele estimar por la crítica, con Pedro Crespo, sino también con los soldados y los nobles militares (se declara capaz de echarlos a todos a cuchilladas, pero pasa al lado disimulando, por cobardía: vv. 1305 y ss., 1423-24), creando así, dentro de los límites de Zalamea, un verdadero microcosmos social y estamental, en el que los villanos han de soportar las demasías de diversas especies de nobles degenerados, a los que se oponen también los buenos militares como don Lope de Figueroa.

\subsection{No hay cosa como callar y La fuerza de la sangre}

A pesar de las extensas páginas que dedica ter Horst a la comparación entre La fuerza de la sangre y No hay cosa como callar, la calidad cervantina de la comedia calderoniana es, de nuevo, perceptible, pero no determinante. El trabajo del estudioso mencionado $^{31}$ se centra en su mayor parte en análisis independientes de ambas obras, sin que quede muy clara una conexión fundamental, y menos en el concepto del honor, que es uno de los pilares de la comparación de ter Horst. La trama de ambas piezas tiene evidentes puntos de contacto: en las dos una dama es forzada en circunstancias con aspectos similares, por un caballero de baja catadura moral, que luego abandona a la mujer (uno se va a Italia, otro a la batalla de Fuenterrabía); en las dos la dama se apodera de un objeto (crucifijo en Cervantes, venera de Santiago en Calderón) que servirá para el reconocimiento del violador; en las dos el conflicto de la mujer deshonrada es el eje fundamental de la trama, junto con la exploración de los roles sexuales, sociales, etc. Pero pronto se advierten las diferencias: como señala con perspicacia ter Horst, la familia y los sentimientos familiares son esenciales en la novela cervantina. De hecho el título hace referencia al misterioso sentimiento que experimenta el abuelo del hijo de Leocadia al verlo herido en la calle; sin conocer al muchacho siente la llamada de la sangre, y ahí comienza el proceso hacia el desenlace. En la comedia de Calderón no existe esta familia que constituye el entorno íntimo de Leocadia ni desempeña función alguna el motivo de la fuerza de la sangre. El gran tema del silencio, que es otro elemento que ter Horst considera esencial en la relación de las dos obras,

31 VER TER HORST, 1982b, p. 35: «the great and powerfull No hay cosa como callar is rather closely modelled on La fuerza de la sangre»; y sobre todo 1982a, pp. 69-170. 
tiene un tratamiento y función completamente distinto, no advertido por el crítico mencionado. En el caso de Leocadia el silencio o secreto no se produce en el seno de su familia, a la que declara su atropello y de la que recibe apoyo. El silencio atañe a la publicidad exterior, para evitar la propagación de la deshonra, según reflexiona Leocadia: «es mejor la deshonra que se ignora que la honra que está puesta en opinión de las gentes», "yo te perdono la ofensa que me has hecho con solo que me prometas y jures que, como la has cubierto con esta escuridad, la cubrirás con perpetuo silencio» ${ }^{32}$, etc. Pero en cuanto regresa a su casa se retira con sus padres "y allí, en breves palabras, les dio cuenta de todo su desastrado suceso» (p. 118), revelación a la que los padres reaccionan en el mismo sentido que ella lo había hecho: «más lastima una onza de deshonra pública que una arroba de infamia secreta. Y pues puedes vivir honrada con Dios en público, no te pene estar deshonrada contigo en secreto; la verdadera deshonra está en el pecado y la verdadera honra en la virtud» (p. 119). La Leonor calderoniana no tiene este recurso: su silencio debe ser absoluto. En trances de honor «no hay cosa como callar», muy especialmente ante su hermano don Diego. El proceso que afecta a Leonor es un proceso de aislamiento comunicativo, reductor y trágico, sin paliativos. La trama se aleja del análisis psicológico y emotivo de las relaciones familiares (fundamental en Cervantes) para apelar a la construcción de una compleja intriga con azares y concentración de relaciones interpersonales que densifican el clima de enredo: todos los personajes principales tienen contacto entre sí, de manera que cada acción provoca una reacción en cadena. Don Diego es hermano de Leonor, amigo de don Luis, el cual es pretendiente de Leonor y amigo de don Juan. Don Juan es el violador de Leonor y pretendiente de Marcela; en el desarrollo de la trama se hace amigo de don Diego, el cual se enamora de Marcela... Las posibilidades de conflictos se multiplican en este esquema de red combinatoria característica de la comedia de enredo $^{33}$. Sin embargo No hay cosa como callar no es una comedia de capa y espada, no participa de la esencia lúdica del género. Un detalle que sirve como pista es la duración de la acción durante varios meses (a diferencia de la restricción temporal máxima de la comedia típica de capa y espada, que no suele pasar de tres días) ${ }^{34}$,

$32 \quad$ La fuerza de la sangre, pp. 114-15.

33 El mismo objeto de reconocimiento que en Cervantes obedece a esta clara función, en Calderón sirve al enredo, cambiando la venera fortuitamente de mano en mano (Comedias, p. 1028).

${ }_{34}$ Comedias, p. 1012, al comienzo del segundo acto se nos dice que han pasado dos meses en los que la melancolía ha dominado a Leonor. La duración es necesaria para dar la idea del efecto que la violación tiene sobre el ánimo de Leo- 
prolongación necesaria para comunicar el sentido de la melancolía que afecta a la protagonista a causa de su deshonra, que va a destruir sus posibilidades vitales. En efecto, aunque los dos desenlaces, en Cervantes y Calderón, son ambiguos (no parece que el Rodolfo de La fuerza de la sangre vaya a ser un buen marido y un buen padre) el de Calderón es más negativo: don Luis y Leonor, que se amaban, no se pueden casar; Marcela, que amaba a don Juan, lo pierde (y tampoco se explicita que vaya a casarse con don Diego); obligada por el azar de la coyuntura a declararse, Leonor empieza el relato de su agravio, interrumpido por don Juan, que le da mano de esposo; esta boda no es ninguna solución a los conflictos; la frustración general es el resultado, y el silencio persiste más allá de este momento en todos los personajes; el silencio se ha extendido sobre todos, el aislamiento contamina también a todos los personajes, cuyas últimas palabras son todas en apartes:

$\begin{array}{ll}\text { JUAN. } & \begin{array}{l}\text { Todo este suceso } \\ \text { ni mi padre, ni tu hermano, } \\ \text { ni ninguno ha de saberlo, } \\ \text { porque si es trance de honor } \\ \text { dice un discreto proverbio } \\ \text { «No hay cosa como callar». }\end{array} \\ \ldots & \begin{array}{l}\text { Supuesto que a Leonor pierdo } \\ \text { y ya es mujer de un amigo, } \\ \text { callemos, celos, que en esto } \\ \text { no hay cosa como callar. }\end{array} \\ \text { DIEGO. } & \begin{array}{l}\text { No alcanzo nada al secreto, } \\ \text { mas pues está remediado } \\ \text { mi honor, que es lo que pretendo } \\ \text { no hay cosa como callar. }\end{array} \\ \ldots & \text { Y yo escarmentada, viendo } \\ \text { MARCELA. } & \text { (Comedias, p. 1037) } \\ & \text { solo ha de ser mi consuelo. }\end{array}$

Como en otros casos la integración de algunos motivos cervantinos se desarrolla de acuerdo con estructuras dramáticas propias que definen las adaptaciones.

nor. Sobre la duración de la acción de capa y espada y su sentido ver ARELlaNo, 1999, pp. 42-52. 


\subsection{La Mojiganga de las visiones de la muerte y la aventura de la} carreta de las Cortes de la Muerte (Quijote, II, 11)

Uno de los casos más interesantes en este sentido es la adaptación de algunos elementos de la aventura de la carreta de las Cortes de la Muerte en la estupenda mojiganga calderoniana de las Visiones de la Muerte. Se ha subrayado la verdad histórica y detallismo documental en la descripción de la carreta de actores del Quijote; los personajes corresponden a los de un auto con estructura de las danzas de la muerte medievales: Rey, Reina, Cupido, la Muerte... y el bojiganga que espanta las monturas y hace caer a don Quijote, el cual sale también de esta aventura maltrecho. Dejando ahora a un lado la trascendencia de este episodio en la economía global de la novela que no me compete examinar, sí puede afirmarse que se trata de un episodio eminentemente 'realista'. Don Quijote acepta pronto que no es una visión fantástica, sino una carreta de actores, y el resto del episodio se centra en la actuación del moharrache carnavalesco, con el resultado sabido.

Muy distinto es el clima de la pieza calderoniana. Un caminante se echa a dormir después de haber bebido y es despertado por el ruido de una carreta de actores que ha volcado en el camino a un pueblo cercano, donde se dirigían a representar un auto, como en el Quijote, por lo que no se han quitado los vestidos de la obra. El caminante, en la bruma del sueño y la bebida, presencia a esta serie de personajes que instauran además el motivo carnavalesco del mundo al revés: un ángel que jura y reniega, un diablo que se persigna... La escena que en el Quijote se presentaba completa desde el comienzo, se desarrolla en la mojiganga de Calderón según un mecanismo teatral en el que la palabra engendra la acción: cada vez que el asustado caminante invoca a los ángeles o a las ánimas del purgatorio, se produce la salida sorprendente de un ángel o el alma del auto, que rompen todas sus expectativas. La música refuerza la dimensión escénica (música de mojiganga, tonadillas, canto de gitanos y gallegos...) y todo se ordena según una estética grotesca que parodia al mismo género del auto sacramental. Una de las características principales del auto es su continuidad espacial y temporal libérrima, pues la alegoría no se sujeta a normas de tiempo y espacio: en esta mojiganga a través de las visiones del caminante borracho se expresa una continuidad del sueño, la fantasía, lo real y el mundo ultraterreno en una parodia genial que culmina en el acto carnavalesco de beber todos a la salud de la muerte, conjurada así por el gesto vital. Bajtín ${ }^{35}$ ha estudiado este

${ }^{35}$ BAJTín, 1974, pp. 265 y 269. 
aspecto en las misas paródicas de borrachines (Missa de potatoribus), y sobre todo en la farsa del XVI, Les morts vivants, que revela bien este sentido, al presentar un abogado que se cree muerto, y al que convencen de que los muertos deben reír, comer y beber; cuando el «muerto" se pone a comer y beber sana definitivamente. La alimentación y la bebida triunfan de la muerte, que bebe en esta mojiganga como los demás.

\subsection{El dragoncillo y La cueva de Salamanca}

El mismo desarrollo teatral en la vía de lo grotesco se percibe en la la última adaptación de la que me ocuparé, la de La cueva de Salamanca en El dragoncillo calderoniano. Es un caso excelentemente analizado por Canavaggio ${ }^{36}$, lo que me exime de extenderme demasiado. Cannavagio advierte que ambos argumentos son una variación del tema del marido burlado, más literaria en Cervantes, más teatral en Calderón. En El dragoncillo se reduce la nómina de personajes, suprimiendo al barbero, y se eliminan las justificaciones verosimilizadoras de Cervantes, ateniéndose en mayor medida al esquema del cuento tradicional, desarrollando sobre todo los elementos del disparate grotesco, con chistes, caricaturas, latinajos y ritos burlescos, como el conjuro. Expansión, en suma, de los aspectos lúdicos y escénicos.

Algunos detalles en los que merece la pena reparar en $E l d r a-$ goncillo, son la parodia de los motivos del honor ${ }^{37}$, la presencia de la música, el ritmo más aclerado que en Cervantes, el refuerzo de los elementos carnavalescos, como el del banquete (mucho más detallado en El dragoncillo, donde hay un amplio desarrollo escénico de los comestibles), y la gran intensidad de la dimensión grotesca y disparatada que se manifiesta por ejemplo en los respectivos conjuros con que estudiante y dragoncillo hacen salir a los supuestos diablos con sus provisiones para cenar. El conjuro cervantino era ya una parodia de Juan de Mena ${ }^{38}$ :

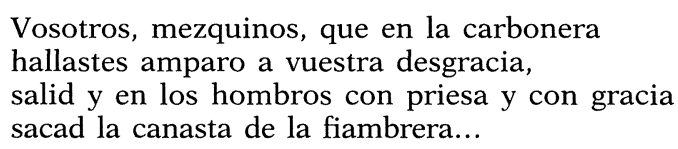

(Teatro completo, p. 822)

\footnotetext{
36 Cannavagio, 1988

37 Ver por ejemplo, vv. 121: "La llave de mi honor, mujer, es esta», 189-90: «iAy, polilla / del honor, y cuánto escarbas!», etc.

38 Conjuro de la maga de Valladolid, Laberinto de Fortuna, estrofa 247.
} 
Pero el del dragoncillo ${ }^{39}$, que hace repetir al marido, es ya un disparate total, con un grado extremo de desarticulación lingüística:

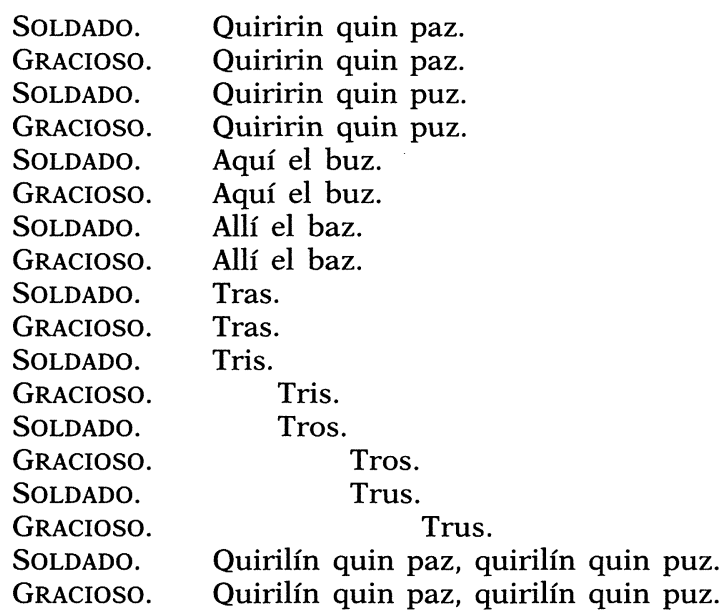

El final calderoniano con truenos y cohetes insiste en este clima de grotesco escénico.

Coincidencias que proceden de un mismo fondo común, otras que provienen de la imitación cervantina, y nuevas diferencias peculiares marcan esta reescritura, que en palabras de Canavaggio ${ }^{40}$ «ilustra a su modo esta relación ambigua que mantiene con los entremeses cervantinos el teatro menor de los tiempos de Felipe IV... en este caso se trata de la labor de un gran poeta que fue, a la vez, admirador del autor del Quijote. De ahí la marca cervantina que el lector atento descubre en una serie de indicios que son como otros tantos guiños de Calderón... Más que reminiscencias son citas que el dramaturgo introduce a su antojo, sin llegar a barajar los naipes, pero haciendo, sí, nuevo reparto».

\subsection{Algunas precisiones hipotéticas sobre la comedia perdida de Don Quijote de la Mancha o Los disparates de don Quijote}

Terminaré con una coda obligada sobre la comedia perdida de Calderón titulada Don Quijote de la Mancha o, según otros testimonios, Los disparates de don Quijote, que Vera Tassis pensaba incluir en la nunca publicada Décima parte de comedias de Calderón.

39 Entremeses, jácaras y mojigangas, ed. RODRÍGUEZ Y TORDERA, pp. 273-74.

40 Cannavaggio, 1988, pp. 14-15. 
Sabemos, por distintos documentos ${ }^{41}$, que se estrenó en palacio en 1637. Sobre este texto perdido los estudiosos han apuntado algunas observaciones que quizá convenga matizar. Sánchez ${ }^{42}$ lamenta su pérdida, ya que en ella efectivamente, tendríamos el testimonio más directo de la influencia cervantina y "conoceríamos la interpretación calderoniana del ingenioso hidalgo", la cual supone de gran densidad poética y hondura caracterológica. López Estrada ${ }^{43}$ le atribuye un lugar entre las pocas que interpretarían con seriedad la obra de Cervantes, que serían en realidad solo dos, la de Guillén de Castro y, supone, esta de Calderón.

Aunque no conocemos el texto, existen las suficientes pistas para estar bastante seguros de que ni Sánchez ni López Estrada aciertan al suponer seriedad en esa comedia, que era, sin duda, una comedia burlesca o de disparates (como indica uno de los títulos que se le atribuyen), y que habría de reflejar una interpretación puramente jocosa y sin mayor preocupación por la coherencia argumental, de las aventuras de don Quijote. Todos los datos paralelos que pueden aducirse apuntan en esa dirección. La comedia de Guillén de Castro, por ejemplo, titulada Don Quijote de la Mancha, que es para López Estrada una comedia seria, merece una precisión: la parte seria trata la historia de Cardenio, mientras que las apariciones de don Quijote son siempre apariciones burlescas de un personaje figura, es decir, ridículo. Versiones ridículas son también las de piezas menores como el Entremés famoso de los invencibles hechos de don Quijote de la Mancha de Francisco de Ávila, la mojiganga Don Pascual del Rábano, o la comedia de disparates Aventuras verdaderas del segundo don Quijote, de un tal Castillo, citada por Rius, y mencionada, como las otras, en el trabajo de López Estrada.

Ridículas son las apariciones de don Quijote y Sancho en las fiestas y mascaradas que conocemos ${ }^{44}$, como la descrita por Pinheiro da Veiga y celebrada en Valladolid en 1605, en la que ya aparece un don Quijote con un sombrero grande en la cabeza y una capa de bayeta batiendo las ijadas a un pobre cuartago sucio con mataduras; o la que describe Salazar ${ }^{45}$ de las fiestas que hizo el Colegio de los jesuitas de Salamanca en la beatificación de Ignacio de Loyola, donde aparece un don Quijote en un rocín como un dromedario, con «una lanza de un palo tiznado con un cuerno de

41 Ver Wilson, 1982, p 10. Calderón la cita en la lista de sus comedias que envió al duque de Veragua en 1680, y en otra anterior entregada por don Franscisco Marañón a Carlos II.

42 SÁNCHEZ, 1957, p. 270.

43 LÓPEZ EsTRADA, 1982, p. 323, y nota 96.

44 Ver LOBATO, 1994 y TORRES, 1999.

45 Ver texto pertinente en LoBato, 1994, pp. 586-87. 
cabrón por hierro». Le acompañan Sancho Panza con alforjas y dos grandes cuernos emplumados, y una Dulcinea en borrico, con botones de conchas de río y medias naranjas, y una bota de vino en la mano que le servía de abanico...

Todas estas presencias quijotescas pertenecen a modelos carnavalescos y ridículos, y revelan un tipo de lectura cómica constante que nos permite inferir, por vía indirecta, pero con bastante probabilidad, el tipo de obra que era la perdida comedia de Don Quijote de la Mancha de Calderón.

\section{CONCLUSIONES}

En conclusión podemos resumir que el número de referencias concretas a Cervantes o su obra en el teatro de Calderón es bastante elevado, pero en buena parte están constituidas por menciones momentáneas que revisten poca funcionalidad o trascendencia. Otro tipo de posibles concomitancias estribadas en toda una cosmovisión, estructuras mentales o artísticas amplias, etc., son muy difíciles de precisar. Dentro de las referencias efectivamente discernibles las hay microtextuales y otras que se desarrollan a lo largo de escenas o piezas completas.

Entre las primeras predominan las evocaciones de don Quijote como personaje, sin que falte la de algún episodio de la novela (aventura de los molinos de viento, la cueva de Montesinos...), Son ocurrencias de cariz burlesco, con varios niveles y mecanismos de adaptación (mención general, pie para el ingenio neológico, chiste anacrónico, caracterización de personajes...), y atribuidas en su mayoría a locutores de donaire. Las menciones relativas a las $\mathrm{No}$ velas ejemplares y otros textos muestran semejantes funciones y técnicas de integración.

Son más productivos los casos macrotextuales, que afectan al Quijote (protagonista y episodios concretos como el de Clavileño o la carreta de las Cortes de la Muerte), a la novela ejemplar de $L a$ fuerza de la sangre, la comedia La casa de los celos, y el entremés de La cueva de Salamanca. En todos estos se percibe mejor el sentido de las adaptaciones o intertextualidades calderonianas, que son definidas por una elaboración propiamente teatral, insertando motivos novelísticos o incluso elementos del teatro cervantino en nuevos esquemas dramáticos, más dinámicos y complejos, que privilegian las dimensiones escénicas y musicales, y en los que el género receptor marca intensamente las posibilidades de renovación del texto referido, como demuestra, por ejemplo, la integración de 
motivos de La Numancia en El sitio de Bredá, o de La fuerza de la sangre en No hay cosa como callar, por poner dos ejemplos.

Los dos ingenios muestran, a pesar de sus grandes diferencias, un deseo común, bien logrado, de multiplicar los niveles de sentido, el juego intertextual y la plurisignificación. Pero el examen de estas actitudes creadoras iría mucho más lejos de mi modesto objetivo en la presente oportunidad, que ha sido simplemente revisar el estado de la cuestión añadiendo algunas elementales glosas sobre la presencia de Cervantes en la obra de Calderón.

IgNACIO ARELLANO

Universidad de Navarra

\section{BIBLIOGRAFÍA CITADA}

ABRAMS, F., «Imaginería y aspectos temáticos del Quijote en El alcalde de Zalamea», Duquesne Hispanic Review, 5, 1966, pp. 27-34.

AREllano, I., "Del relato al teatro: la reescritura de El curioso impertinente cervantino por Guillén de Castro», Criticón, 72, 1998, pp. 73-92.

- Convención y recepción. Estudios sobre el teatro del Siglo de Oro. Madrid, Gredos, 1999.

BAJTín, M., La cultura popular en la Edad Media y en el Renacimiento. Barcelona, Barral, 1974.

Calderón, Pedro, El alcalde de Zalamea, ed. J. M. Escudero. Madrid, Iberoamericana, 1998.

- Entremeses, jácaras y mojigangas, ed. E. Rodríguez y A. Tordera. Madrid, Castalia, 1982.

- La púrpura de la rosa, ed. Á. Cardona, D. Cruickshank y M. Cunningham. Kassel, Reichenberger, 1990.

- Obras completas. Comedias, ed. Á. Valbuena Briones. Madrid, Aguilar, 1973.

- Obras completas. Dramas, ed. Á. Valbuena Briones. Madrid, Aguilar, 1987.

CANAVAgGio, J., "En torno al Dragoncillo. Nuevo examen de una reescritura», en Estudios sobre Calderón, ed. A. Navarro. Salamanca, Universidad, 1988, pp. 9-16.

CARo BARoJA, J., Vidas mágicas e Inquisición. Madrid, Istmo, 1992, 2 vols.

CAstro, Guillén DE, Don Quijote de la Mancha, ed. L. García Lorenzo. Salamanca, Anaya, 1971.

Cervantes, Miguel DE, Don Quijote de la Mancha, ed. dirigida por F. Rico. Barcelona, Crítica-Instituto Cervantes, 1998.

- La fuerza de la sangre, en Obra completa, 8, ed. F. Sevilla y A. Rey Hazas. Madrid, Alianza, 1996.

- Teatro completo, ed. F. Sevilla y A. Rey Hazas. Barcelona, Planeta, 1987.

Chauchadis, C., La loi du duel. Le code du point d'honneur dans l'Espagne des XVIXVII siècles. Toulouse, PUM, 1997.

GonzÁlez RovirA, J., La novela bizantina de la Edad de Oro. Madrid, Gredos, 1996. Herrero García, M., Estimaciones literarias del siglo XVII. Madrid, 1930.

HORST, R. TER, "A New Literary History of Don Pedro Calderón», en Approaches to the Theater of Calderón, ed. M. D. McGaha. Washington, University Press of America, 1982b, pp. 33-42. 
- Calderón: The Secular Plays. Lexington, The University Press of Kentucky, 1982a.

LoBATo, M. L., "El Quijote en las mascaradas populares del siglo XVII», en Cervantes. Estudios reunidos en la víspera de su centenario, II. Kassel, Reichenberger, 1994, pp. 577-604.

LÓPEZ EstradA, F., «Fiestas y literatura en los Siglos de Oro. La Edad Media como asunto festivo (El caso del Quijote)», Bulletin Hispanique, 84, 1982, pp. 291-327.

NaVArro GonZÁleZ, A., El "Quijote» español del siglo XVII. Madrid, 1964.

PAILlER, C., "El gracioso y los "guiños" de Calderón: apuntes sobre "autoburla" e ironía crítica», en Risa y sociedad en el teatro español del Siglo de Oro, varios autores. Paris, CNRS, 1980, pp. 33-48.

REICHENBERGER, K., "Calderón ¿persona non grata?», en Pedro Calderón de la Barca. El teatro como representación y fusión de las artes, Anthropos, Extra 1, 1988, pp. 30-31.

RiUS, L., Bibliografía crítica de las obras de Miguel de Cervantes Saavedra. Madrid, Lib. Murillo, 1895-1905, 3 vols.

SÁNCHEZ, A., "Reminiscencias cervantinas en el teatro de Calderón», Anales cervantinos, 6, 1957, pp. 262-70.

TORRES, J. C. DE, “"Enquijotóse mi amo” o el tema del caballero idealista en las comedias de Calderón», Actas del tercer congreso internacional de la asociación de cervantistas (III-CINDAC). Mallorca, Universidad de las Islas Baleares, 1998, pp. 619-29.

TORRES, L., "Las fiestas paródicas en la corte de Valladolid a través de las relaciones de sucesos», en La fiesta, ed. S. López Poza y N. Peña. La Coruña, Sociedad de Cultura Valle Inclán, 1999, pp. 339-50.

WILSON, E. M., "Calderón y Cervantes», Hacia Calderón. V Coloquio anglogermano, ed. H. Flasche y R. D. F. Pring-Mill. Wiesbaden, Franz Steiner, 1982, pp. 9-19. 